\title{
An Investigation of the Ectoparasites of Slaughtered Cattle at Keffi Abattoir in Nassarawa State of Nigeria, Sub-Sahara Africa
}

\author{
Mukhtar O. Adamu, Abdullahi S. Onawo, Fatimat O. Adebayo* \\ Department of Microbiology, Nassarawa State University, Keffi, Nigeria \\ Email address: \\ adamuowuna@gmail.com (M. O. Adamu), aisha2016feb@gmail.com (F. O. Adebayo) \\ ${ }^{*}$ Corresponding author
}

\section{To cite this article:}

Mukhtar O. Adamu, Abdullahi S. Onawo, Fatimat O. Adebayo. An Investigation of the Ectoparasites of Slaughtered Cattle at Keffi Abattoir in Nassarawa State of Nigeria, Sub-Sahara Africa. International Journal of Animal Science and Technology. Vol. 2, No. 1, 2018, pp. 18-22. doi: $10.11648 /$ j.ijast.20180201.14

Received: November 21, 2017; Accepted: December 9, 2017; Published: January 19, 2018

\begin{abstract}
Ectoparasites represent a major source of livestock productivity loss. This study assessed different types as well as the predilection sites of ectoparasites on slaughtered cattle at Keffi abattoir. The fleas and lice were collected by combing the skin of the animal, while the ticks were carefully picked using a forceps. The ectoparasites found were preserved in $10 \%$ formalin in a sample tube and identified using standard techniques. A total of 300 cattle were surveyed, of which 202(67.33\%) were infested with varieties of ectoparasites while $98(32.67 \%)$ were not infested. Nonetheless, $139(68.81 \%)$ of the cattle were infested with ticks of which 95(47.03\%) represents Rhipicephalus spp. while only 44(21.78\%) represents Amblyomma spp., while about one-fifth, 57(28.22\%) of the infestation were caused by fleas; of which $39(19.31 \%)$ were of the Ctenocephalides canis while $18(8.91 \%)$ were of the Ctenocephalides felis. However, $6(2.97 \%)$ of the infestation were due to Linognathus vituli specie of louse. Majority of the infestation were at the thigh, abdomen, neck and back. Using $X^{2}$ analysis, the findings showed that there was a statistical significant difference between the prevalence of the ectoparasites by species, while no significant association was found with respect to the number of cattle infested by sex of the cattle surveyed and also by locations of survey. This study revealed a higher prevalence of ectoparasites of cattle in Keffi metropolis; infestation was found to be predominantly by two tick species: Amyblyomma spp. and Rhipicephalus spp. Thus cattle should be checked and treated regularly for ectoparasites as infestation may affect their health, productivity as well as the economic value of these animals.
\end{abstract}

Keywords: Ectoparasites, Slaughtered Cattle, Keffi Abattoir, Animal Protein, Predilection Site, Tick

\section{Introduction}

Parasitic diseases of livestock significantly impact negatively on the animal's wellbeing and productivity. A parasite is therefore a small organism that feeds and nourishes on or in and at the expense of a larger organism, called the host [1] [2]. By effect, the presence of a parasite may be detrimental, indifferent or beneficial to the host. Parasites are grouped according to location as ectoparasites and endoparasites. Ectoparasite include those organisms (e.g. ticks, lice, mites, flies) living on the surface of the host where they derive food, shelter and other basic needs to survive [3]. Conversely, endoparasites are those organisms (e.g. protozoa, helminths) that live inside the body of the host [4]. Ectoparasites are widespread, often highly damaging and in most cases cannot be permanently eradicated. Ectoparasites are of two types namely: facultative and obligate ectoparasites. Facultative ectoparasites exhibit both parasitic and non-parasitic mode of living, hence do not absolutely depend on parasitic way of life. They are capable of behaving as parasites only if they are placed on a host. Obligate ectoparasites on the other hand are completely dependent on the host during a segment of their life cycle [5]. In addition to their direct effect on the host, ectoparasites indirectly release pathogens thereby acting as vectors of diseases [6].

Ectoparasites are also thought to play a key role in reducing the quality of hides by injection of the animal skin [7]. Ectoparasitism represents a major obstacle to development and utilization of animal resources alongside huge livestock production losses [4] [8]. It is noteworthy that 
while the parasites enjoy shelter and nourishment, the host in turn receives secretion, excretion as well as trauma [9] [10]. Moreover, some of the substances secreted by the parasites were shown to be antigenic and are therefore capable of eliciting allergic and immune reactions [11]. Hence the negative impact of ectoparasites in cattle could be overwhelming. This translates to lose of weight, restlessness, growth retardation, weakness and anaemia due to excessive sucking of blood from the host by the parasites [12]. More so, some ectoparasites represents good sources of zoonotic parasites to man. Thus they have the potential to transmit viral, fungal, bacterial, and protozoan diseases which in turn results into mortality in severe cases [13] [14].

In Nigeria, cattle constitute the main source of animal protein [11]. Furthermore, the skin derived from cattle, goats and sheep are frequently used for the manufacture of leather in Europe and other part of the world [15]. Research has shown that before the oil boom years, hides and skins constituted a major foreign exchange of Nigeria. In addition, by-products such as hide and skin, blood, hoofs, horns and bones are often converted into various finished products. Hide and skin have been used for making shoes, leather bags, etc [5]. Interestingly, waste products in form of dung can be distributed over farmland as organic (or farm yard) manure to keep the soil at a satisfactory physicochemical conditions and maintain its nutrients supply at a desirable level. It is also important to state that, of the varieties of ectoparasites, ticks stand out as the most notorious threat due to severe irritation, allergy and toxiosis [16]; they further identified ticks as the major causes of low productivity and mortality in their host, worse still, they serve as reservoirs and vectors for a number of protozoa, viruses, rickettsia and bacteria; thus capable of transmitting diseases viz. babesiosis, theileriosis, anaplasmosis and tick-borne relapsing fever.

Consequently, for the fact that cattle produce the greatest percentage of the bulk of animal protein consumed by the over 180 million population of Nigeria, a study of ectoparasites and pests is critical to enhance their control and improve the quality of cattle industry in Nigeria.

\section{Materials and Methods}

\subsection{Study Area}

This study was conducted in Keffi local Government Area of Nasarawa State, Nigeria. Keffi is located in the middle zone of Nigeria and lies between latitude $08^{\circ} 59^{\prime} 55^{\prime}$ North and longitude of $52^{\prime} 25^{\prime}$ 'East with area of $137 \mathrm{~km}^{2}$ [17]. Keffi has two constituencies Keffi East and Keffi west, it has ten geopolitical wards with a population of 92,664 at the 2006 census [18]. The area is located with tropical sub-humid climate belt. It is made up of two seasons namely: Rainy season and dry season. The rainy seasons last for about seven months usually from April to October with a mean annual rainfall of about $1000 \mathrm{~mm}-1600 \mathrm{~mm}$ which peaks around July to August. Temperature here generally ranges from $28^{\circ} \mathrm{C}-$ $39^{\circ} \mathrm{C}$. Relative humidity increases during the rainy season with a record of about $94 \%$ in August and drop to 5\% in harmattan period and vegetation pattern of the area is made up of grasses, shrubs and isolated big trees a typical example of wood land savannah vegetation belt of Nigeria [18].

\subsection{Method of Collection}

The cattle's skin were examined thoroughly by close inspection and parting the hairs against their natural direction for the direction of ectoparasites. The ectoparasite (ticks) was collected by forceful detachment as earlier described by [19], while fleas and lice were collected by combing the skin of the animal before collection accordingly. Thereafter, ectoparasites obtained were preserved in $10 \%$ formalin in a sample tube. The samples were collected from abattoir at Tsohon Kasuwa (Old Market) within Keffi Metropolis, Keffi Local Government Area of Nassarawa State, Nigeria.

\subsection{Identification of Samples}

Morphological characterization and identification of ticks were made by using the standard manual guide of [7] and observation was carried out using magnifying hand lens and compound microscopes. Lice and Fleas samples were examined directly under a compound microscope as described by a standard manual of [20].

\subsection{Statistical Analysis}

The data collected were analyzed using the Statistical Package for the Social Science (SPSS) version 22.0. Chisquare test was used to determine significance difference between different types of ectoparasites and also the predilection sites of infestation.

\section{Results}

This research examined 300 cattle from June, 2017 to August, 2017. Of the $300(100 \%)$ cattle surveyed, 202 $(67.33 \%)$ were infested with varieties of ectoparasites while $98(32.67 \%)$ were not (Table 1$)$. There is no significance difference in the prevalence of ectoparasites on cattle $(\mathrm{P}>0.05)$.

Table 2 shows that majority $139(68.81 \%)$ of the cattle were infested with ticks of which $95(47.03 \%)$ represents Rhipicephalus spp. while only $44(21.78 \%)$ represents Amblyomma spp. More than one-fifth 57 (28.22\%) of the infestation were caused by fleas; whereby 39 (19.31\%) were of the Ctenocephalides canis while $18(8.91 \%)$ were of the Ctenocephalides felis. Another 6 (2.97\%) of the infestation were due to Linognathus vituli specie of lice (Table 2). There is a significant difference between the different ectoparasites of cattle encountered.

As indicated in table 3, majority of the cattle examined were males 237 (79\%) while only $73(21.0 \%)$ were females. There was no significance difference between the male and female cattle sampled $(\mathrm{P}<0.05)$.

In table 4 , the result of sex-based infestation is shown. About $122(60.40 \%)$ of the $237(79.0 \%)$ bulls examined were 
infested with various varieties of the ectoparasites, while 80 $(39.60 \%)$ of the $73(21.0 \%)$ cows examined were also infested with different varieties of the ectoparasites. There was no significance difference between the male and female cattle sampled.

Table 5 shows the location or site of infestation by different ectoparasites. Majority of the infestation were to the thigh, abdomen, neck and back. There was no significance difference between the ectoparasite based on location of infestation.

\section{Discussion}

This study assessed varieties of ectoparasites prevalent on slaughtered cattle in Keffi abattoir within the period of June, 2017 to August, 2017. This study revealed that $67.33 \%$ of the cattle were infested with the varieties of the ectoparasites examined. This is higher than the $44.4 \%$ reported by [21] in Dodoru market, Kebbi State, Nigeria and $47.0 \%$ asserted by [22] in Central Ethiopia. Why this discrepancy existed is not known, nonetheless, it is appropriate to state that seasonal variations and possibly environmental factors may have played important role in the distribution of these ectoparasites investigated.

Similarly, the study showed higher prevalence rate when compared with the work of [8] who reported prevalence rate of $27.3 \%$ in Bench Maji zone, Southwestern Ethiopia. More so, in this report, tick infestation was the outstanding $(68.81 \%)$ followed by fleas $(28.22 \%)$ and then lice $(2.97 \%)$. This concur with the findings that ticks were the most prevalent ectoparasites of livestock [6] [8] [23]. The higher prevalence of ticks in the study area could be attributed to the fact that tick infestation tends to be higher during the wet season under which the study was conducted compared to dry season [1].

Furthermore, the prevalence of ticks was shown to be higher while lice were shown to be lower this is comparable to the findings of [8].

Table 1. Prevalence of cattle infested with ectoparasites in Keffi abattoir.

\begin{tabular}{lll}
\hline Variables & Number Sampled & Percentage (\%) \\
\hline Cattle infested & 202 & 67.33 \\
Cattle not infested & 98 & 32.67 \\
Total & 300 & 100.0 \\
& $X^{2}=1.5789$ & $\mathrm{P}=0.3594$ \\
\hline
\end{tabular}

Table 2. Prevalence of ectoparasites of cattle in Keffi abattoir.

\begin{tabular}{lll}
\hline Ectoparasites & No. of cattle with ectoparasites (\%) & No. of ectoparasites collected (\%) \\
\hline Ticks & & \\
Rhipicephalus spp. & $70(34.65)$ & $95(47.03)$ \\
Amblyomma spp. & $69(34.16)$ & $44(21.78)$ \\
Fleas & & \\
Ctenocephalides felis & $29(14.36)$ & $18(8.91)$ \\
Ctenocephalides canis & $28(13.86)$ & $39(19.31)$ \\
Lice Linognathus vituli & $6(2.97)$ & $6(2.97)$ \\
Total & $202(100.0)$ & $202(100.0)$ \\
& $X^{2}=2.6407$ & $\mathrm{P}=0.0575$ \\
\hline
\end{tabular}

Table 3. Number of animals examined based on sex.

\begin{tabular}{lll}
\hline Sex & Number Sampled & Percentage (\%) \\
\hline Male & 237 & 79.0 \\
Female & 73 & 21.0 \\
Total & 300 & 100.0 \\
& $X^{2}=1.8902$ & $\mathrm{P}=0.06098$ \\
\hline
\end{tabular}

Table 4. Infestation of cattle based on sex.

\begin{tabular}{|c|c|c|c|c|c|}
\hline \multirow{2}{*}{ Sex } & \multirow{2}{*}{$\begin{array}{l}\text { Number Examined } \\
(\%)\end{array}$} & \multicolumn{4}{|c|}{ Ectoparasites } \\
\hline & & Ticks & Lice & Fleas & $\%$ \\
\hline Male & $237(79.0)$ & 72 & 03 & 47 & 60.40 \\
\hline Female & $73(21.0)$ & 67 & 03 & 10 & 39.60 \\
\hline \multirow[t]{2}{*}{ Total } & $300(100.0)$ & 139 & 06 & 57 & 100.0 \\
\hline & $X^{2}=1.6833$ & $\mathrm{P}=0.3413$ & & & \\
\hline
\end{tabular}

Table 5. Prevalence of ectoparasites based on site/location of infestation.

\begin{tabular}{llll}
\hline Ectoparasites & Predilection sites & No Examined & Prevalence (\%) \\
\hline & & & 68.81 \\
\hline Ticks & Thigh, abdomen, neck, back & 139 & 28.22 \\
Fleas & Thigh, abdomen, neck, tail & 57 & 2.97 \\
Lice & Abdomen, ear, back, trunk & 06 & 100.0 \\
Total & & 202 & $\mathrm{P}=0.2243$ \\
& & $X^{2}=1.7381$ & \\
\hline
\end{tabular}


However, [5] revealed a higher prevalence of ticks $(73.3 \%)$ relative to the findings of this study. Contrary to the findings of this research, [8] indicated prevalence rate of mite to be $3.4 \%$. It is important to stress that mites are a special group of ectoparasites; their presence of whom is largely dependent on the ideal macro and micro environment (high temperature, humidity and sunlight) which favors their breeding and multiplication in the study area.

Furthermore, of the different species of tick investigated Rhipicephalus spp. (Formally known as Boophilus spp.) was shown to be higher (47.03\%) than the Amblyomma spp. $(21.78 \%)$. This is in agreement with previous research such as [8] who asserted that Rhipicephalus spp. is the predominant cause of tick infestation in cattle. Reference [3] also indicated a lower prevalence of Rhipicephalus spp. $(36.89 \%)$. This trend is strongly supported by the assertion that the dominance of Boophilus (Rhipicephalus spp.) was because of the native distribution of tick on distribution of host species and climate condition [24]. Furthermore, chisquare test showed no statistical differences in the occurrence of ectoparasites of cattle in the study area.

In addition, this study found prevalence rate of lice to be $2.97 \%$. This is far below the $9.5 \%$ reported by [14] and $10.4 \%$ reported by [8]. This disparity could be attributed to differences in the agro-ecology, climatic condition and sample size used in the study area. Similarly, this research found the prevalence of fleas to be $28.22 \%$. This is far below the $35.7 \%$ reported by [25] in Gondar town, Ethiopia. Moreover, $79.7 \%$ of the males examined were infested with the varieties of ectoparasites compared to the females $(20.3 \%)$. This is not consistent with the findings of [8] who reported the prevalence rate of ectoparasites of male and female cattle to be $25.0 \%$ and $39.1 \%$ respectively. Further research is however recommended to assess the prevalence of ectoparasites on cattle based on sex.

On the basis of site or location of infestation, this present study demonstrates that majority of the infestation is on the thigh, abdomen and neck. This is in line with the findings of prior research. For instance, [25] reported that thigh/abdomen were more likely to be the most preferred locations for ectoparasites infestation. Similarly, [5] observed ectoparasites in all parts of the cattle notably; trunk, ears, tail, perineum. The propellant activity of the tail may serve to ward off harbored parasites thus it is not so much a favorable site of infestation.

\section{Conclusion and Recommendation}

This study revealed a higher prevalence of ectoparasites of cattle in Keffi metropolis; infestation was found to be predominantly by two main tick species: Amyblyomma spp, and Rhipicephalus spp. Two fleas species, i.e. Ctenocephalides felis, Ctenocephalides canis, one louse species Linognathus vituli. Common predilection sites of infestation were found to be the thigh and abdomen of the cattle. More so, not much is known about ectoparasites infestation in Keffi metropolis; thus further study is recommended to investigate the extent of damages caused by these ectoparasites and to establish control measures. Based on the findings of this study, the following are recommended: cattle should be regularly checked and treated for ectoparasites, as infestation may affect their health, productivity and economic value; treatment should be focus on predilection sites of the host's body infested by ectoparasites such as thigh, abdomen and back; and apart from the control of the parasite on the body of the host, areas where host graze or sleep should also be considered for treatment for effective control of the parasites.

\section{References}

[1] Shiferaw, D. and Abebe, G. (2006). Cattle tick dynamics in different agro-ecological zones of Wolayta, Southern Ethiopia. Ethiopian Veterinary Journal, 10: 85-99.

[2] Wall, R., Rose, H., Ellse, L. and Morgan, E. (2011). Livestock ectoparasites integrated management in a changing climate. Veterinary Parasitology, 180: 82-89.

[3] Rony, S. A., Mondal, M. M. H., Begum, N., Islam, M. A. and Affroze, S. (2010). Epidemiology of ectoparasitic infestations in cattle at Bhawal Forest Area, Gazipur, Bangladesh. Journal of Veterinary Medicine, 8: 27-33.

[4] Wall, R. (2007). Ectoparasites: future challenges in a changing world. Veterinary Parasitology, 148: 62-74.

[5] Tongjura, J. D. C., Amuga, G. A., Ombugadu, R. J., Aamu, Y. and Mafuyai, H. B. (2012). Ectoparasites infesting livestock in three local government areas of Nasarawa State, Nigeria. Science World Journal, 7(1): 15-17.

[6] Ayele, S., Asegid, W., Abera, M. A., Ahmed, M. M. and Belachew, H. (2003). Livestock marketing in Ethiopia. A view of structure, performance and development initiatives. SocioEconomic and Policy Research Work Paper, Nairobi, Kenya. 52: 121 .

[7] Walker, A. R., Bouattour, A., Camicas, J. L., Estrada-pena, A., Horak, I. G., Latif, A. A, Pedgram R. G. and Preston, P. M. (2003). Ticks of Domestic Animals in Africa: A Guide to Identification of Species, Bioscience Reports, Edinburgh, UK. Pp. 24-67.

[8] Onu, S. H. and Shiferaw, T. Z. (2012). Prevalence of ectoparasite infestations of cattle in Bench Maji Zone, Southwest Ethiopia. Veterinary World, 6(6): 291-294.

[9] Taylor, M. A. (2001). Recent developments in ectoparasiticides. The Veterinary Journal, 161: 253-268. doi:10.1053/tvj1.2000.0549.

[10] Taylor, M. A. (2007). Veterinary Parasitology. Blackwell Publishing, Oxford, United Kingdom. ISBN 978-1-40511964-1.

[11] James-Rugu, N. N. and Jidayi, S. (2004). A survey on the ectoparasites of some livestock from some areas of Borno and Yobe States. Nigerian Veterinary Journal, 25(2): 48-55.

[12] Campbell, J. B. (2002). Livestock Insect of Cattle. Journal of Animal Science, 70(1): 70:4. 
[13] Sonenshine, D. E. (2007). Biology of tick. Oxford University Press, New York. Vol.1 and 2, Pg; 44-45, 465.

[14] Tadesse, A., Fentaw, E., Mekbib, B., Abebe, R., Mekuria, S. and Zeuwdu, E. (2011). Study on the prevalence of ectoparasite infestation of ruminants in and around Kombolcha Tannary, Northeastern Ethiopia. Ethiopian Veterinary Journal, 15: 87-101.

[15] Stork, M. G. (1979). The epidemiological and economic importance of fly infestation of meat and milk producing animals in Europe. Veterinarian Reviewed, 105: 341-343.

[16] Jongejan, F. and Uilenberg, G. (2004). The global importance of ticks. Parasitology, 129(1): 3-14.

[17] Nassarawa Geographical Information Services (NAGIS) (2015). GPS map of Nasarawa State showing all the Local Government Areas. www.nagis.gov.ng

[18] Akwa, V. L., Binbol, N. L., Samaila, K. L. and Marcus, N. D. (2007). Geographical perspective of Nasarawa State. Onaivi Printing and Publishers Ltd Keffi, Nigeria.

[19] James-Rugu, N. N. and Iwuala, M. O. E. (1998). Studies on the prevalence and factors conditioning ticks infestation of dogs, sheep and goat in Plateau State. Journal of Innovation in Life Science, 10: 20-30.
[20] Mathison, B. A. and Pritt, B. S. (2014). Laboratory identification of Arthropod Ectoparasite. Clinical Microbiology Review, 27(1): 56-64.

[21] Yahaya, M. A., Magami, I. M. and Bagida, I. M. (2015). Prevalence of ticks on camels and cattles brought to Dodoru Market Kebbi State, Nigeria. Journal of Agriculture, 2(4): 1624.

[22] Gebreselama, M., Zeru, F. and Rohma, G. (2014). Identification and prevalence of ectoparasites in cattle and sheep in and around Bishoftu town, Central Ethiopia. Animal and Veterinary Sciences, 2(4): 124-129.

[23] Niratu, K. and Teshome, F. (2012). Population dynamics of cattle ectoparasite in Western Amhara National Region State, Ethiopia. Journal Veterinary Medical Animal Health, 4: 2226.

[24] Pergam, G., Hoogsstraal, H. and Wassef, H. (1981). Tick Argasidae ixodidae of Ethiopia, distribution, ecology and host relationship of species infecting livestock. Bulletin of Entomology Research, 71: 339-359.

[25] Fantahun, B. and Mohamed A. (2012). Survey on the distribution of tick species in and around Assosa town, Ethiopia. Research Journal Veterinary Science, 5: 32-41. 